\title{
Tribological Characteristic Evaluation of Tungsten Disulfide Solid Lubrication Films
}

\author{
By Ayaka TAKAHASHI ${ }^{1)}$ and Keizo HASHIMOTO ${ }^{1)}$ \\ 1) Graduate School of Science and Engineering, Teikyo University, Utsunomiya, Japan
}

(Received June 13th, 2013)

\begin{abstract}
To be used in severe outer space environments, spacecraft may also cause unexpected problems from the ground level. In order to solve the problems, it is important that many of the sliding portions of the spacecraft have been prepared by the lubrication processing. A solid lubricant is suitable in the space environment such as a low pressure and wide temperature changes. Gold film and molybdenum disulfide have been mainly utilized for solid lubricant in spacecraft. These materials have been already examined the tribological characteristics using the variety of additives. Although these lubricants have been applied in the various space environments, tungsten disulfide which has the same crystal structure as molybdenum disulfide has not been studied intensively. In this study, tungsten disulfide has been examined for the application of the solid lubricant in the spacecraft. In order to simulate the deployment friction, the reciprocating tribometer experiments were conducted in a vacuum and air using the aluminum alloy and the stainless steel substrates coated by tungsten disulfide. It was found that the tungsten disulfide lubricant coating have demonstrated the lowest friction coefficient among other solid lubricants. But it also reached its wear life before the end of test duration in a vacuum. To improve the wear life of tungsten disulfide, substrates which coated by mixture of tungsten disulfide powder and polyamideimide have been studied. Comparisons of the two coating methods have been elucidated in conjunction with wear morphology observed by EDS-SEM.
\end{abstract}

Key Words: Solid Lubricant, Tungsten Disulfide, Friction, Space Lubricant

\section{Introduction}

Basically, drive equipment for spacecraft cannot be taken maintenance and inspection after the launch. Problem that did not occur on the ground level may occur in the space because environment of spacecraft is special extreme such as a low pressure, wide temperature change and severe radiations. Therefore development and design of the spacecraft will be required to withstand against harsh environments without maintenance during operation. We should be noted in particular phenomenon is adhesion ${ }^{1)}$. It occurs in the following cases: the oxide layer and adsorbed molecular layer on the outermost surface is lost, moreover, when metal surface of each other are in the contact and the strong bonding (metallic bond, covalent bond, ionic bond). And the other phenomenon is cold welding ${ }^{2,3)}$. When the smooth metal surfaces contact with each other in a vacuum environment, cold welding also occurs in atomic level (The phenomenon itself has not been fully elucidated). Lubricating treatment is commonly used at the sliding portion as a method of preventing adhesion and cold welding besides that is also used for the purpose of smooth operation of the sliding portion.

Solid lubricant such as gold ( $\mathrm{Au}$ ) film and molybdenum disulfide $\left(\mathrm{MoS}_{2}\right)$ have been mainly utilized in the current spacecraft. These materials have been studied extensively about the tribological characteristics using the combination of variety of additives. Although these lubricants have been applied in the severe space environment, tungsten disulfide $\left(\mathrm{WS}_{2}\right)$ which has the same unique crystal structure (layered structure) as $\mathrm{MoS}_{2}$ has not been studied intensively.

In this study, $\mathrm{WS}_{2}$ have been examined for the application of the solid lubricant in the spacecraft. If the lubricant that can reduce the contact resistance in the severe environment once developed, it can be strongly contributed to the reliable spacecraft operations.

\section{Experimental Procedure}

The friction coefficient of the solid lubricant that has been mainly utilized in spacecraft and the $\mathrm{WS}_{2}$ itself has been evaluated. The performance of lubrication in the simple substance. Then $\mathrm{WS}_{2}$ lubricant sample using a binder, compared with the type of $\mathrm{WS}_{2}$ alone. Two types of $\mathrm{WS}_{2}$ lubricant were examined and evaluated in different conditions using a reciprocating tribometer with vacuum chamber.

\subsection{Tungsten disulfide}

$\mathrm{WS}_{2}$ was commercially available as powder form since $\mathrm{WS}_{2}$ powder is utilized in the automobile industry. $\mathrm{WS}_{2}$ has the same crystal structure as $\mathrm{MoS}_{2}$ like graphite structure. Basal plane consisting Tungsten (W) and sulphur (S) atom bond by the covalent bond, however, two basal planes bond by Vander-Waals force. Physical properties are listed in Table. 1.

Table 1. Physical properties of $\mathrm{WS}_{2}$ and $\mathrm{MoS}_{2}$.

\begin{tabular}{|l|c|c|}
\hline & $\mathrm{WS}_{2}$ & $\mathrm{MoS}_{2}$ \\
\hline Density/g/cm3 & 7.5 & 5.06 \\
\hline Decomposition temperature/K & 1523 & 1458 \\
\hline Mohs hardness & $1 \sim 1.5$ & $1 \sim 1.5$ \\
\hline Purity & 99.999 & 99.9 \\
\hline
\end{tabular}




\subsection{Tested specimen}

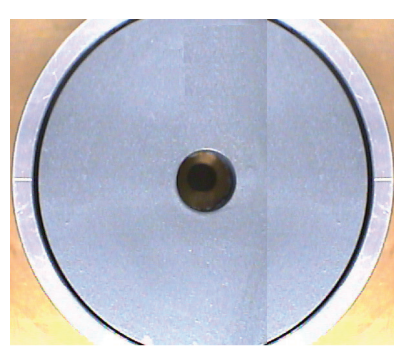

Fig. 1. $\mathrm{WS}_{2}$-B specimen.
Four types of solid lubricants designated $\mathrm{Au}$, $\mathrm{MoS}_{2}, \quad \mathrm{WS}_{2}-\mathrm{A}$ and $\mathrm{WS}_{2}-\mathrm{B}$ have been tested. Their lubricant, binder and additives are listed in Table 2. $\mathrm{Au}$ and $\mathrm{MoS}_{2}$ are using past research of result ${ }^{4,5)}$. $\mathrm{WS}_{2}-\mathrm{A}$ and $\mathrm{WS}_{2}-\mathrm{B}$ are tested newly in this study.

Substrate and counterpart (ball; $8 \mathrm{~mm}$ diameter) materials are commercial aluminum alloy and stainless steel. They are machined $45 \mathrm{~mm}$ diameter $8 \mathrm{~mm}$ thickness. Surfaces of material were carefully polished by the same finishing condition. Au film was deposited by the electro-chemical technique. $\mathrm{MoS}_{2}$ film was coated on substrate followed by heat treatment. $\mathrm{WS}_{2}$-A was coated on substrate by thumping method in the chamber. In the case of $\mathrm{WS}_{2}-\mathrm{B}, \mathrm{WS}_{2}$ powder and liquid type of polyamideimide (PAI) were mixing mechanically, substrate disc dipped into sol (mixture of $\mathrm{WS}_{2}$ and polymer), following dry and heat treatment at $473 \mathrm{~K}$ in air. Figure 1 shows the photograph of $\mathrm{WS}_{2}-\mathrm{B}$ specimen.

Table 2. Combination of lubricant, binder and additives.

\begin{tabular}{|c|c|c|c|}
\hline Name & Lubricants & Binder & Additives \\
\hline $\mathrm{Au}$ & $\mathrm{Au}$ & $\mathrm{Ni}$ & $\mathrm{Co}$ \\
\hline $\mathrm{MoS}_{2}$ & $\mathrm{MoS}_{2}$ & Polymer & Graphite \\
\hline $\mathrm{WS}_{2}-\mathrm{A}$ & $\mathrm{WS}_{2}$ & - & - \\
\hline $\mathrm{WS}_{2}$-B & $\mathrm{WS}_{2}$ & Polymer & - \\
\hline
\end{tabular}

Table 3. Tested conditions.

\begin{tabular}{|l|l|}
\hline Load & $1 \mathrm{~N}$ \\
\hline Number of strokes & $5000(2500$ strokes $)$ \\
\hline Test environments & Air, Vacuum \\
\hline Vacuum level & On the order $10^{-4}-10^{-6} \mathrm{~Pa}$ \\
\hline $\begin{array}{l}\text { Disk substrate materials } \\
\text { counterpart materials }\end{array}$ & $\begin{array}{l}\text { Stainless steel } \\
\text { Aluminum alloy }\end{array}$ \\
\hline
\end{tabular}
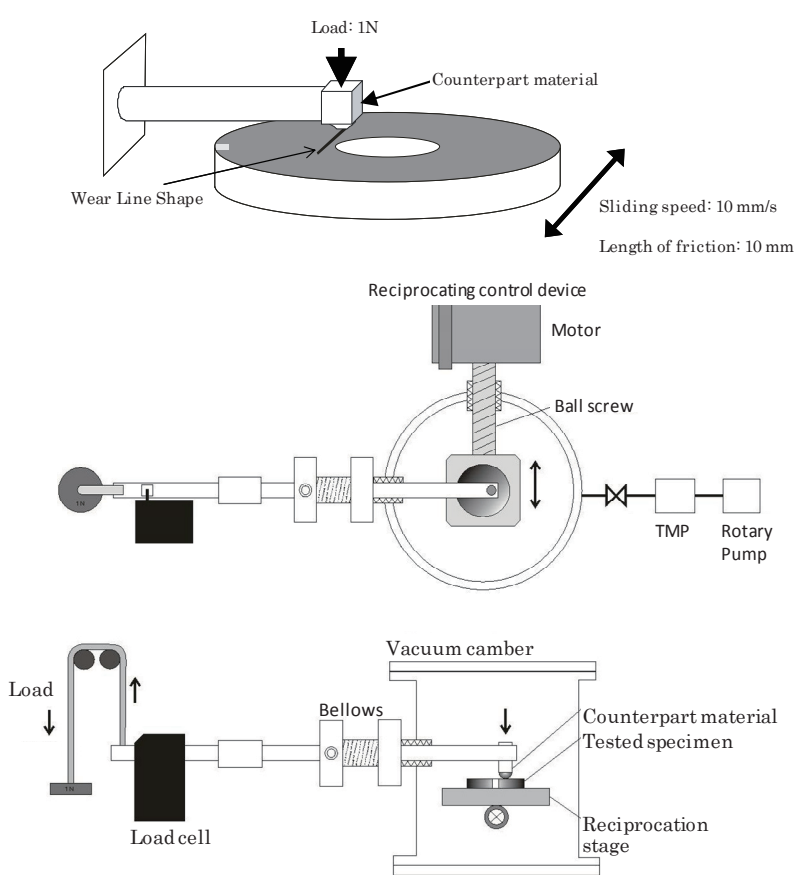

Fig. 2. Overview of reciprocating tribological test.

\subsection{Tribological tests}

A pin-on-disk type friction test was carried out using a reciprocating tribometer to investigate the friction characteristics of various types of lubricant coatings, in the air and in a vacuum. Figures 2 show a schematic diagram of the reciprocating tribometer, which can evaluate friction under a constant applied load and sliding speed. The tribometer was installed inside a vacuum chamber to allow tests to be carried out in the air and in a vacuum. A counterpart pin slides repeatedly against a disk coated with lubricant, with a load of $1 \mathrm{~N}$ applied by a weight located outside the vacuum chamber. The speed of the sliding is controlled by the reciprocating motion of the disk specimen. The test conditions are shown in Table. 3. The sliding speed and length were $10 \mathrm{~mm} / \mathrm{s}$ and 10 $\mathrm{mm}$, respectively. For tests under vacuum conditions, the chamber was evacuated by a turbo molecular pump to a pressure on the order of $10^{-4}-10^{-6} \mathrm{~Pa}$. The friction test was continued for a nominal 5,000 sliding strokes, but was interrupted when the friction became high or it was suspected that the wear may have reached the substrate of the disk.

\section{Results and Discussion}

Pin-on-disk tests were conducted for $\mathrm{WS}_{2}-\mathrm{A}$ and $\mathrm{WS}_{2}-\mathrm{B}$ films against aluminum alloy and stainless steel counterparts and substrate in vacuum conditions. In order to evaluate the lubricating performance of the $\mathrm{WS}_{2}$, comparison with results of our past research at the same conditions, $\mathrm{MoS}_{2}$ and $\mathrm{Au}$ lubrication which are known at the space lubricant have been examined. The friction behaviors of each counterpart material in vacuum are shown in Figs. 3 and 4.

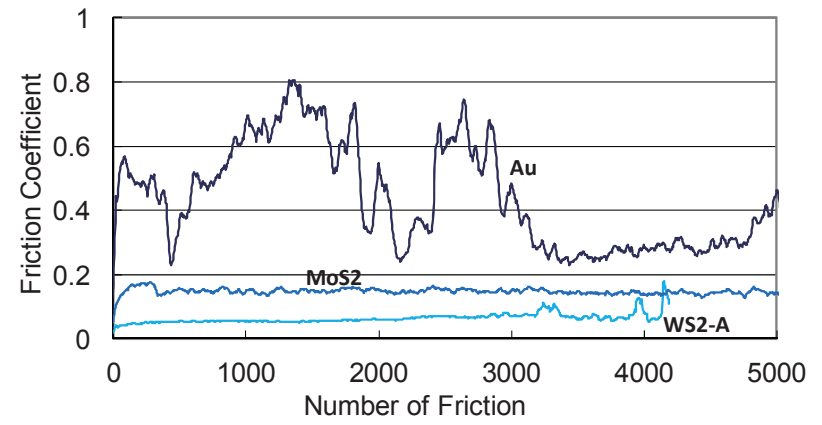

Fig. 3. Friction coefficient changes of $\mathrm{Au}, \mathrm{MoS}_{2}$ and $\mathrm{WS}_{2}$ during friction cycles in a vacuum. (Counterpart and substrate materials: Aluminum alloy)

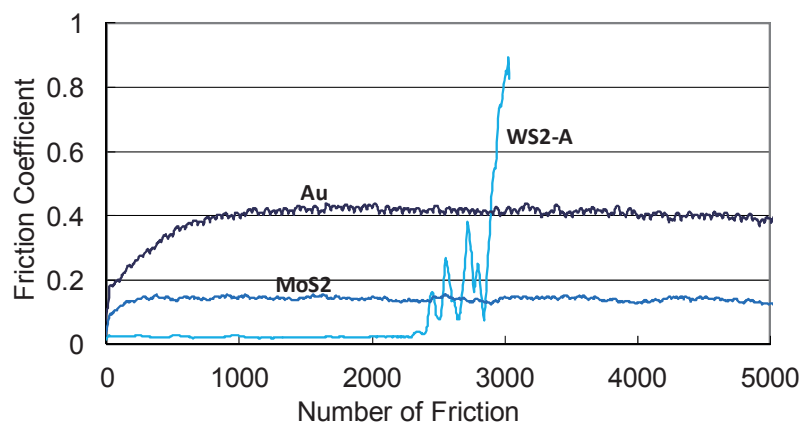

Fig. 4. Friction coefficient changes of $\mathrm{Au}, \mathrm{MoS}_{2}$ and $\mathrm{WS}_{2}$ during friction cycles in a vacuum. Counterpart and substrate materials: Stainless steel) 


\subsection{Friction coefficient}

Friction force monitored by load cell during friction test and it converted to friction coefficient. Figure 3 and 4 shows the friction coefficient change in $\mathrm{Au}, \mathrm{MoS}_{2}$ and $\mathrm{WS}_{2}-\mathrm{A}$ during friction test up to 5000 cycles in a vacuum atmosphere. According Fig.3. and 4., $\mathrm{WS}_{2}$ clearly shows the lowest friction coefficient among other solid lubricants such as $\mathrm{Au}$ and $\mathrm{MoS}_{2}$. But it also reached its wear life before the end of test duration in a vacuum. These results suggest that $\mathrm{WS}_{2}$ has a potential of excellent solid lubricant but its coating method has not been established yet. Because of very thin $\mathrm{WS}_{2}$ film on the substrate, wear life become shorter than $\mathrm{MoS}_{2}$ film.

In order to form more thicker $\mathrm{WS}_{2}$ film, $\mathrm{WS}_{2}$ powder and liquid type of polyamidimide were mixed and make thicker film than $\mathrm{WS}_{2}$-A specimen. Figure 5 shows friction behavior of $\mathrm{WS}_{2}-\mathrm{A}$ and $\mathrm{WS}_{2}-\mathrm{B}$ in air with different substrate and counterparts. Although $\mathrm{WS}_{2}-\mathrm{B}$ show higher friction coefficient than $\mathrm{WS}_{2}-\mathrm{A}$, wear life is improved up to 5000 cycles. Figure 6 demonstrates that friction behavior of $\mathrm{WS}_{2}-\mathrm{A}$ and $\mathrm{WS}_{2}-\mathrm{B}$ in a vacuum with different substrate and counterparts. Friction behaviors are quite similar in both environments. There are two important factors to improve both friction coefficient and wear life. One is the volume fraction of $\mathrm{WS}_{2}$ in the polymer matrix the other is the thickness of $\mathrm{WS}_{2}$ film. In this study, these factors have not been examined to find out the most suitable film conditions.

\subsection{EDS analysis}

Friction behaviors of $\mathrm{WS}_{2}-\mathrm{A}$ and $\mathrm{WS}_{2}-\mathrm{B}$ films have demonstrated the two extreme cases. To clarify the friction behaviors of $\mathrm{WS}_{2}-\mathrm{A}$ and $\mathrm{WS}_{2}-\mathrm{B}$, scanning electron microscope (SEM) observations have been carried out. SEM-DES analysis have been identified the existing atomic elements on the surfaces. If tungsten (W) has been detected

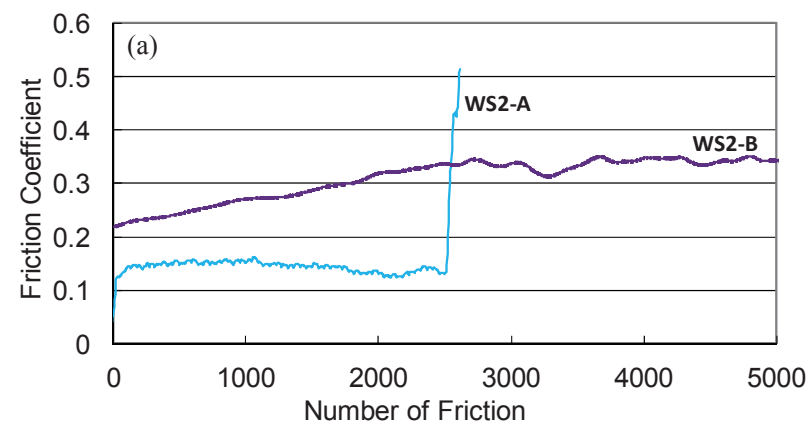

on the ball and on the substrate surface, it is evidence that $\mathrm{WS}_{2}$ is working as solid lubricant continuously. SEM-EDS observations of $\mathrm{WS}_{2}-\mathrm{A}$ specimen are shown in Fig. $7_{-}$(a). Substrate is stainless steel and counterpart is aluminum alloy in Fig.6. Unknown fragments exit on the both substrate and counterpart surfaces after reached wear cycle limit. It can be concluded that $\mathrm{WS}_{2}$ film on the substrate has worked as an excellent lubricant but peeled off during tribological tests. Binding force between $\mathrm{WS}_{2}$ and substrate is not enough to keep $\mathrm{WS}_{2}$ film on the surface in the case of WS2-A sample coated by the thumping method.

Figure 7_ (b) show the SEM-EDS observations of $\mathrm{WS}_{2}-\mathrm{B}$ specimen. Substrate is stainless steel and counterpart is aluminum alloy in Fig.6. SEM micrograph shows rather smaller wear area than $\mathrm{WS}_{2}$-A in Fig.6. This observation is indicating that contacting surface of counterpart (ball) is more narrow area than that of $\mathrm{WS}_{2}-\mathrm{A}$. Surface morphology of substrate in $\mathrm{WS}_{2}$-B specimen shows uniform depth without fragmentation. EDS analysis of $\mathrm{W}$ element is indicating that W element exist on both substrate and counterpart surfaces. $\mathrm{WS}_{2}$ is maintained lubrication characteristic.

\subsection{Environmental effects}

$\mathrm{WS}_{2}$ and PAI composite has been demonstrated longer wear life than that of $\mathrm{WS}_{2}$ alone. Environmental effects were evaluated using different material combinations in air and in a vacuum. Figures 8 and 9 shows the effects of environment and counterpart materials. Substrate material is aluminum alloy shows Fig.8. And Substrate material is stainless steel shows Fig.9. It was found that $\mathrm{WS}_{2}$-B specimens show always lower friction coefficient in a vacuum environment than in air environment at the same material combinations on substrates and counterparts. Friction coefficient behaviors are same

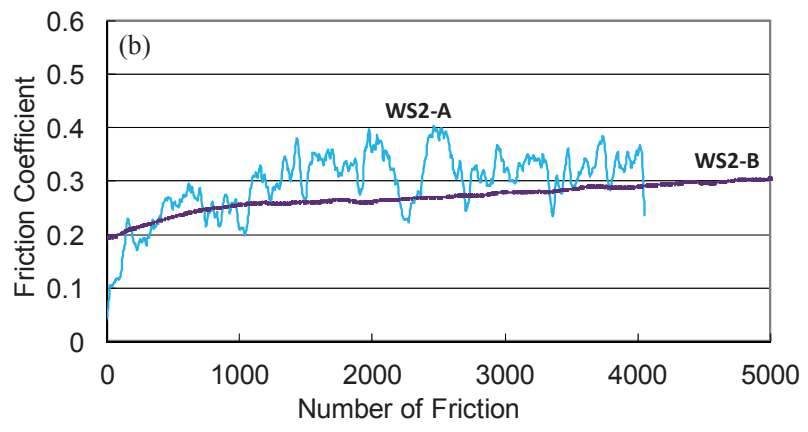

Fig. 5. Friction behaviors of tested coatings with different substrates and counterparts. (Environment/Air)

Substrate/Counterpart /: (a) aluminum alloy / stainless steel, (b) stainless steel /aluminum alloy
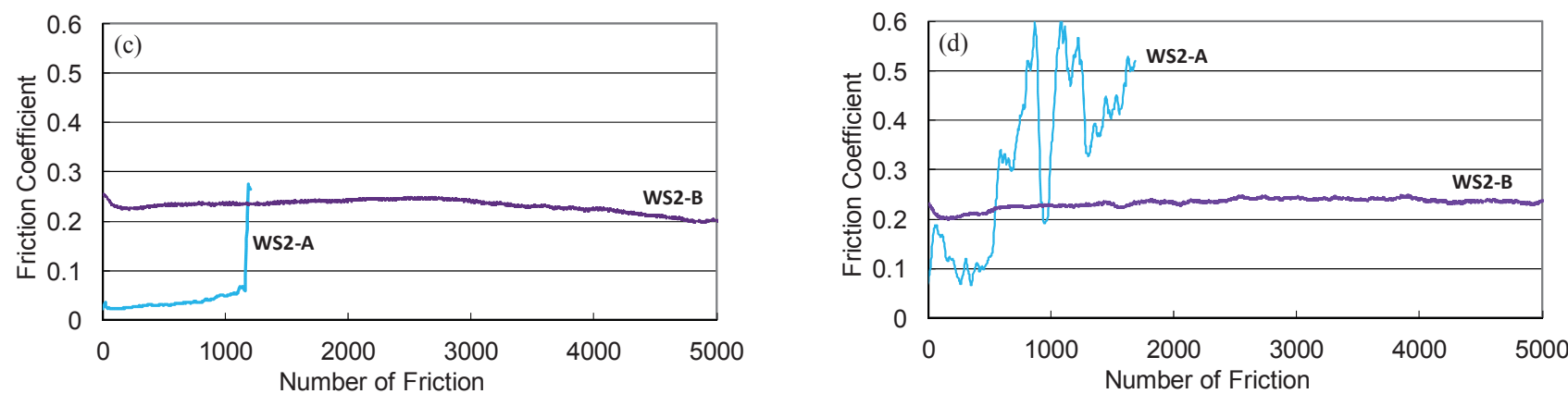

Fig. 6. Friction behaviors of tested coatings with different substrates and counterparts. (Environment/Vacuum)

Substrate/Counterpart: (c) aluminum alloy / stainless steel, (d) stainless steel /aluminum alloy 

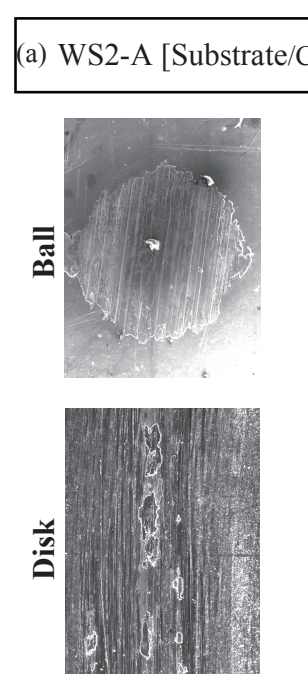

SEM
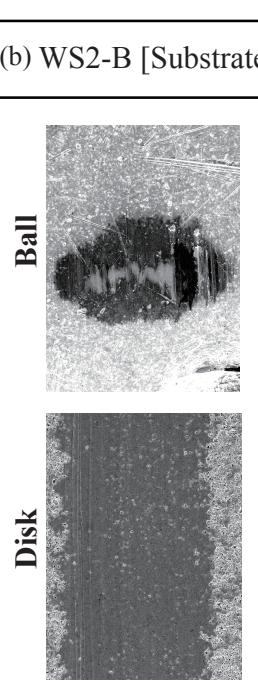

SEM
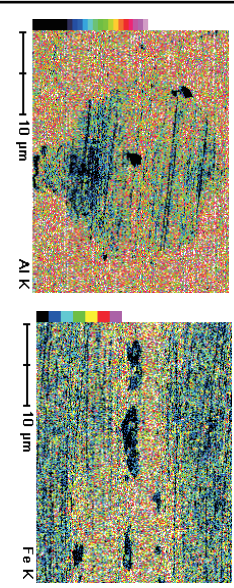

$\mathrm{EDS} \llbracket \mathrm{Fe}, \mathrm{Al} 】$
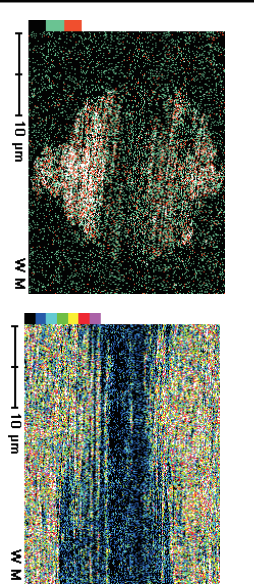

EDS【W】

Fig. 7. SEM-EDS observations of specimen.

Substrate is stainless steel and counterpart is aluminum alloy

regardless of the difference in substrate material.

\section{Conclusions}

In order to evaluate the lubricating performance of the $\mathrm{WS}_{2}$, two types $\mathrm{WS}_{2}$ lubricant films have been compared with results of $\mathrm{MoS}_{2}$ lubricating and Au lubrication with the same conditions in our past research.

- $\mathrm{WS}_{2}$-A show the low friction coefficient among another lubricants in a vacuum, but short lubricant life.

- The friction characteristic of $\mathrm{WS}_{2}-\mathrm{B}$ is stable and long term.

- $\mathrm{WS}_{2}-\mathrm{B}$ is hard to unaffected by the environment and substrate/counterpart materials.

\section{Further study}

In this study, two types of tungsten disulfide solid lubricant were investigated by a pin-on-disk type friction tests in a

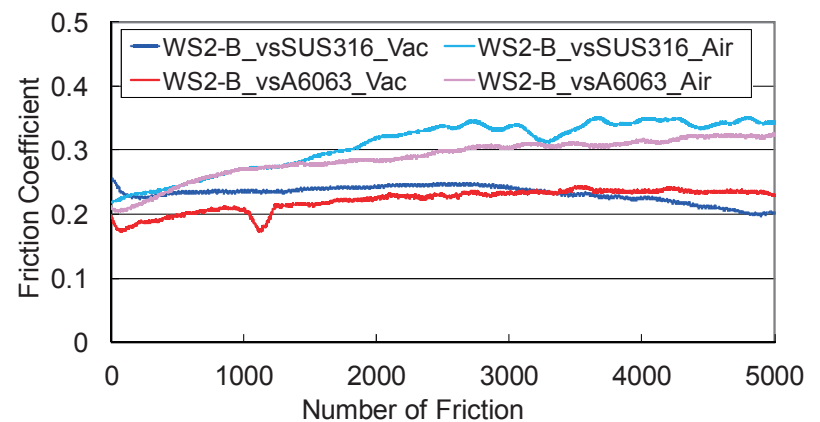

Fig. 8. Friction changes of $\mathrm{WS}_{2}-\mathrm{B}$ for each counterpart material and environment. (Substrate: aluminum alloy)

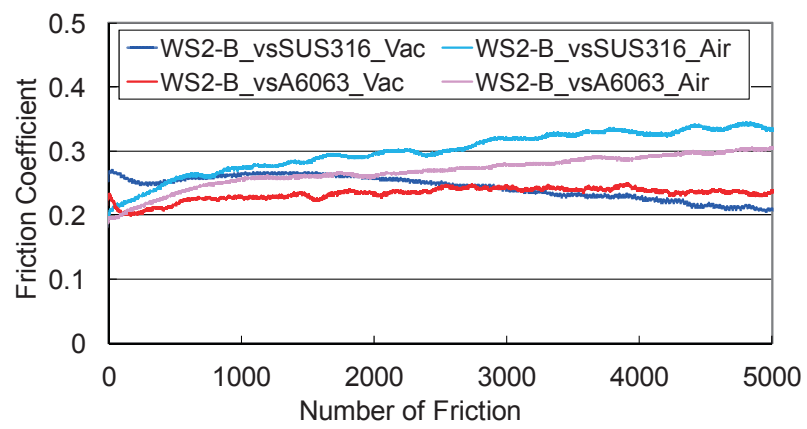

Fig. 9. Friction changes of $\mathrm{WS}_{2}-\mathrm{B}$ for each counterpart material and environment. (Substrate: stainless steel)

vacuum. It is necessary to simulation test the space environments (Atomic oxygen, cycle of high and low temperature or each, space radiation, etc...) in order to evaluate as the space lubricant. On the basis of the tested results, establishment of the coating method is also essential.

\section{Acknowledgments}

Authors express appreciation to Dr. K. Matsumoto at JAXA for tribology tests and helpful discussions. $\mathrm{WS}_{2}$ powder was provided by Mr. Y. Fukuda at Wada-trading Inc. PAI materials was provided by Nippon Kodoshi Corp.

\section{References}

1) Jones Jr., W. R. and Jansen, M. J. : Space Tribology, NASA/ TM-2000-209924, 2000.

2) Eugene, C. and Noland, M. C. : Cold Welding Tendencies and Frictional Studies of Clean Metals in Ultra-High Vacuum, ASLE TRANSACTIONS, 10, pp. 146-157, 1967.

3) Ferguson, G. S., Chaudhury, M. K., Sigal, G. B., and Whitesides, G. M. : Contact Adhesion of Thin Gold Films on Elastomeric Supports : Cold Welding Under Ambient Conditions, Science, 253 No.5021, pp.776-778, (1991.)

4) Takahashi, A., Iki, K., Shiomi, H., Matsumoto, K. and Kawamoto, S. : Tribological Experiments for Deployment of Electrodynamic Tether System, 2011-r-34, 28th ISTS, 2011.

5) Matsumoto, K., Tahashi. A., el al. : Performance of Electroconductive Bonded Lubricant Films in Space Environment for Electrodynamic Tether of Debris Removal System, 28th ISMSE, 2012. 